\title{
Evaluation of the efficacy of a carbon brace ('corset monocoque carbone respectant la respiration' [CMCR]) preserving lung capacity to treat idiopathic scoliosis in children and adolescents: a retrospective study of 115 patients
}

\author{
$G_{\text {Notin }}{ }^{*}$, JC Bernard ${ }^{2}$, J Deceuninck ${ }^{2}$
}

From 8th International Conference on Conservative Management of Spinal Deformities and SOSORT 2011

Annual Meeting

Barcelona, Spain. 19-21 May 2011

\section{Objectives}

The purpose of this retrospective study was to investigate whether treatment with a carbon brace stops the progression of idiopathic scoliosis in children and adolescents affected by combined or thoraco-lumbar scoliosis.

\section{Background}

The carbon brace is a single shell corset whose supports are defined according to the $\mathrm{x}$ rays and a 3D reconstruction [1]. Their mobility results from using carbon adjustable strips. The study was carried on a population of 115 scoliotic children whose average age is 12.5 .

\section{Material and methods}

We compared clinical features and radiolographic data at brace set-up and removal in 115 patients with combined or thoracolumbar scoliosis. The impact of the brace was evaluated in 2 subgroups according to their Risser stages. With 95 patients, a questionnaire was used to evaluate the physical and psychological tolerance of the brace.

\section{Results}

At brace set-up, the immediate angular correction was about 50\% compared to the pre-brace angle; the reduction of the vital capacity was weak. After brace removal,

${ }^{1}$ Lecante, Lyon, France

Full list of author information is available at the end of the article radiographic data showed significant improvement in thoraco-lumbar and lumbar curves of patients with combined scoliosis, although the thoracic curvature of the combined scoliosis was unchanged. No significant efficiency on the hump was observed.

\section{Conclusions}

The CMCR can stop the progression of moderate combined or thoracolumbar scoliosis during growth, this type of orthosis provides a better outcome in terms of thoracic mobility and vital capacity, but have little efficacy on the hump. The CMCR brace is indicated for patients with flexible scoliosis. This "mobile" brace has definitely its place in the current therapeutic arsenal.

\section{Author details}

${ }^{1}$ Lecante, Lyon, France. ${ }^{2}$ CMCR des Massues, Lyon, France.

Published: 27 January 2012

\section{Reference}

1. Bernard JC, et al: Evaluation du résultat d'un corset monocoque respectant la respiration (CMCR) dans la scoliose idiopathique chez l'enfant et l'adolescent : étude rétrospective sur 115 patients. Ann Readapt Med Phys 2005, 48(9):637-649.

doi:10.1186/1748-7161-7-S1-048

Cite this article as: Notin et al:: Evaluation of the efficacy of a carbon brace ('corset monocoque carbone respectant la respiration' [CMCR]) preserving lung capacity to treat idiopathic scoliosis in children and adolescents: a retrospective study of 115 patients. Scoliosis 2012 7(Suppl 1):O48

(c) 2012 Notin et al; licensee BioMed Central Ltd. This is an open access article distributed under the terms of the Creative Commons 